\title{
LOS IMPACTOS DE LA IMPUNIDAD EN MÉXICO. REFLEXIONES DESDE UNA PERSPECTIVA DE GÉNERO*
}

\author{
IMPUNITY IMPACT IN MEXICO THOUGHTS FROM A GENRE \\ PERSPECTIVE
}

\section{Alicia Elena PéRez DUARTE y NOROÑA**}

RESUMEN: En este artículo se pretende mostrar los componentes de una normatividad que rige un Estado moderno de derecho en un marco de intercambios y compromisos internacionales cuyo objetivo es el desarrollo de lo que hoy conocemos como derechos humanos, entre cuyos principios está la responsabilidad de ese Estado de garantizar la seguridad de todas las personas que integran su población. Una responsabilidad que, desde el punto de vista de las mujeres, es incumplida de manera sistemática por la frecuencia en que los hechos de violencia contra las mujeres quedan en la impunidad y lo que ello significa para las víctimas en sus vidas debido al impacto tanto de la violencia misma como del significado de la falta de protección del Estado del conjunto de sus derechos humanos.

Palabras clave: derechos humanos, seguridad, impunidad, perspectiva de género, violencia contra las mujeres.
ABSTRACT: In this article we pretend to show the composite parts of the normativity that rules the Modern Law State in the frame of international exchanges and treaties whose goal is to develop what we know now as Human Rights, among whose principles is the State responsability to guarantee the safety and security of every person that integrates the state's population. A responsability that, from the women's point of view, is constantly and systematically broken by the frequency in which acts of gendered violence are left unpunished and what this means for the victims's lives due to the impact the violence had on them as well as what it means to lack the protection that the State should give them as part of their human rights.

Key words: human rights, security, impunity, gender perspective, violence against women.

* Recibido el 6 de octubre de 2020; aprobado el 17 de enero de 2021.

** ORCID: 0000-0001-5695-854X. Feminista; doctora en Derecho por la UNAM; investigadora titular en el Instituto de Investigaciones Jurídicas de la UNAM. Correo electrónico: alicia.elena@comunidad.unam.mx.

Boletín Mexicano de Derecho Comparado, nueva serie, año LIV, núm. 160, enero-abril de 2021, pp. 335-359. 
SUMARIO: I. Introducción: la seguridad responsabilidad del Estado. II. La seguridad desde la perspectiva de las mujeres. III. La percepción social de la impunidad: violencia contra las mujeres. IV. Concepto de impunidad en el ámbito internacional. $\mathrm{V}$. Las recomendaciones de los órganos de control y vigilancia de derechos humanos.

VI. Colofón a manera de conclusiones. VII. Bibliografia.

\section{INTRODUGGIÓN: LA SEGURIDAD RESPONSABILIDAD DEL ESTADO}

Hace algunos años, consideraba que estudiar Derecho, así con mayúsculas, permite tejer certezas, convicciones, verdades absolutas, uno que otro dogma y dejarlos correr por el mundo tratando de esconder todas las dudas que nos asaltan en cada esquina de la vida, porque es más fácil vivir con la seguridad de que las cosas son así porque lo dice la ley, la Constitución, el código o el reglamento, que estar preguntándonos a cada momento ¿es cierto?, ¿puedo?, ¿tiene/tengo/tenemos derecho a, derechos de?

En esta línea de inquietudes alguna vez me pregunté sobre la razón fundamental de ser del Estado moderno, del Estado de derecho, y para tratar de entender esta razón busqué al padre del derecho positivo y de la teoría del Estado: Hans Kelsen. En sus libros, encontré la respuesta, que se puede trasmitir tal cómo la escribió él con cita de pie de página y todo o parafraseando a Antonio Machado: el Estado, estructura político-jurídica, existe porque dondequiera hay gente que quiere danzar, jugar, labrar su palmo de la tierra, beber vino, donde hay vino y donde no, pues agua fresca y alguien o algo tiene que garantizar que puedan hacerlo con toda tranquilidad.

Sí, así es, la base fundamental del Estado moderno es la seguridad. Sobre esta base, se construye toda una estructura institucional que debería garantizar entre otros, los principios de igualdad, no discriminación y respeto por la dignidad y la libertad de las personas, así como están marcados en Ley General de Acceso de las Mujeres a una Vida Libre de Violencia (en adelante Ley General) en relación con las mujeres, porque estos cuatro principios sólo son posibles si todas las personas cuentan con la seguridad de vivir con tranquilidad y sin violencia, en su diversidad.

Sin embargo, cabe preguntar si actualmente esta base está funcionando o bien necesitamos cambiar sus reglas para tener la seguridad que requerimos. La respuesta es más que evidente: en México, bajo muchos

Esta obra está bajo una Licencia Creative Commons

Atribución-NoComercial-SinDerivar 4.0 Internacional, IIJ-UNAM.

Boletín Mexicano de Derecho Comparado, núm. 160, enero-abril de 2021, pp. 335-359. 
pretextos, como la guerra contra el narcotráfico y el crimen organizado emprendida en el gobierno calderonista, la militarización abierta del gobierno de Peña Nieto que se legaliza y continúa en el presente, por ejemplo, tenemos la percepción de que la inseguridad se ha instalado en nuestros espacios, que las instituciones del Estado que deberían garantizarnos esa seguridad son insuficientes.

En el caso de las mujeres, esta percepción tiene una connotación especial cuando se visualiza la inseguridad desde una perspectiva de género, pues las mujeres, sólo por el hecho de serlo, vivimos en una permanente sensación de peligro e inseguridad ahí donde desarrollamos nuestras vidas, el hogar, las escuelas, los centros de trabajo, las iglesias, la vía pública, el transporte también público; es una percepción de constante riesgo, las últimas cifras del secretariado ejecutivo de Seguridad Pública ${ }^{1}$ no dejan mentir: más de diez feminicidios diarios entre enero y octubre de 2020 es aterrador.

En ambos sentidos: la inseguridad social y la inseguridad de las mujeres, son prueba de que existe una fractura que deslegitima toda la estructura del Estado, precisamente porque la impunidad de los actos de violencia - tanto social como de género contra las mujeres - deja sin sentido real tanto las leyes como las instituciones que supuestamente deben servir para prevenir la violencia, para sancionar los hechos violentos y reparar los daños ocasionados.

Es este sentido se han manifestado, también desde otras ciencias. Es el caso de Cabrera:

Desde una perspectiva psicosocial, la legitimidad tiene su anclaje en las creencias sobre el mundo [...] Desde esta perspectiva, nos interesa comprender si la impunidad cuestiona el sentido de la ley y de la justicia, cuando la experiencia de las víctimas queda sometida a un contexto de reiterada impunidad político-legal, manejada por hilos invisibles para evitar o distorsionar la justicia en el enjuiciamiento de las violaciones a los derechos humanos en Guatemala. Esto significa que la negación u obstrucción de justicia impide ejercer la función social de reparación del daño, asumiendo todas las consecuencias psicológicas y políticas que esto implica en la construcción de la democracia (Luisa Cabrera, 2001, p. 39).

1 Información sobre violencia contra las mujeres Incidencia delictiva y llamadas de emergencia 9-1-1. Centro Nacional de Información. Corte al 31 de octubre de 2020.

Esta obra está bajo una Licencia Creative Commons Atribución-NoComercial-SinDerivar 4.0 Internacional, IIJ-UNAM. Boletín Mexicano de Derecho Comparado, núm. 160, enero-abril de 2021, pp. 335-359. 
Reflexión válida para la situación de impunidad que existe en los casos de violencia contra las mujeres en el país, en especial cuando esta impunidad es también un obstáculo a la libertad, en el sentido más amplio que en los últimos años ha retomado la Organización de Naciones Unidas, es decir, esa que "incluye la idea de que el desarrollo, la seguridad y los derechos humanos van de la mano" (Naciones Unidas, 2005; en adelante $\mathrm{ONU})$. Concepto que todavía no es una realidad para cientos de millones de personas en el mundo, por tanto, la impunidad es un atentado no sólo a la seguridad sino también a la libertad, a la igualdad, al desarrollo y, en general, a los derechos humanos.

\section{LA SEGURIDAD DESDE LA PERSPECTIVA DE LAS MUJERES}

Colocando la violencia contra las mujeres como el eje de la reflexión es importante recordar que entre los pactos sociales que construyeron el concepto de Estado tal y como se le entiende actualmente, se determinó, en un momento de la historia, que mediante el matrimonio las mujeres tendríamos seguridad, solidaridad y apoyo, a cambio de nuestros servicios reproductivos. ${ }^{2}$ Sin embargo, en la actualidad, observamos que este acuerdo no ha funcionado pues, si hemos de creer a los llamados datos duros existentes en México - y en el mundo-, cerca de la mitad de las mujeres casadas viven en la inseguridad y el temor precisamente a partir de su matrimonio, ${ }^{3}$

2 Este es el sentido de la obra de Engels El origen de la familia, la propiedad privada y el Estado, sentido y orientación reflexiva que han seguido otras personas estudiosas de las relaciones humanas y que, desde mi punto de vista, se ha desvirtuado porque la inseguridad empieza precisamente en ese ámbito del matrimonio con la idea de que el hombre, por razón de esa protección, asumió el cargo de jefe de la familia y, por tanto tiene derecho a corregir tanto a la mujer/esposa como a sus hijas e hijos; también tiene derecho a manifestar sus frustraciones e enojos de manera violenta o agresiva.

3 En la Encuesta Nacional sobre la Dinámica de las Relaciones en los Hogares (ENDIREH, 2016), se afirma que: "De los 46.5 millones de mujeres de 15 años y más que residen en el país, se estima que 30.7 millones de ellas $(66.1 \%)$ han padecido al menos un incidente de violencia emocional, económica, física, sexual o discriminación en los espacios escolar, laboral, comunitario, familiar o en su relación de pareja. De estos porcentajes, se señala que $43.9 \%$ de la proporción de mujeres de 15 años y más han experimentado violencia por parte de su actual o última pareja, esposo o novio, y que esta violencia incrementa cuando se treta de la segunda o ulterior pareja. Esta violencia lejos de disminuir ha aumentado, como se puede observar en las tres precedentes encuestas. Los datos recabados por la

Esta obra está bajo una Licencia Creative Commons

Atribución-NoComercial-SinDerivar 4.0 Internacional, IIJ-UNAM.

Boletín Mexicano de Derecho Comparado, núm. 160, enero-abril de 2021, pp. 335-359. 
pues es su cónyuge/pareja, su agresor primario, de ahí que el tema de la violencia contra las mujeres haya sido puesto en la agenda pública precisamente a partir de esta relación y de la conjugación del binomio violencia familiar/violencia sexual (véase Organización Mundial de la salud, 2010; 2013a y 2013b).

Desde otro ángulo, reconocemos al derecho penal y a las políticas públicas sobre seguridad y combate al crimen, como una parte del complejo engranaje del control social al que Michel Foucault (1975, pp. 299 y ss.) critica porque no se limita, según él, a actuar sobre el cuerpo de las personas, sino que actúa directamente sobre el "alma" y, según él, la crea.

Reconozco el valor relativo de las afirmaciones de Foucault, y si bien no comparto con él el determinismo rígido y represor que atribuye a las normas de derecho, sí es cierto que, en un Estado moderno, el derecho es el conjunto de reglas, prohibiciones y sanciones que crean una determinada organización del poder, establecen mecanismos de control y vigilancia, así como los sistemas de legitimación de estos mecanismos que dan contenido al concepto de cultura.

Así pues, el derecho es el elemento de lo social que regula la vida de mujeres y hombres y es un conjunto de reglas que uniforma, de una u otra manera, a personas y grupos ofreciéndoles, a cambio, seguridad.

Independientemente de las críticas que podamos hacer al derecho como reproductor de modelos sociales bipolares y excluyentes, la realidad es que por medio de las normas jurídicas tenemos el conjunto de reglas que hacen una voluntad a la que se puede llamar común, pero, para las mujeres, para el ejercicio de nuestro derecho a vivir sin violencia, no es suficiente, el aparato represor no es suficiente para garantizar nuestra seguridad pues se convierte, literalmente, en cómplice protector de los agresores.

Pareciera que reconoce el lenguaje de los mandatos de masculinidad a los que hace referencia Rita Segato (2003), pero no logra interpretar la voz de las mujeres que definen la violencia que se escribe en nuestros cuerpos con conceptos tan claros como "cualquier acción u omisión, basada en su género, que les [a las mujeres] cause daño o sufrimiento psi-

Secretaría de Gobernación, el Instituto Nacional de las Mujeres y ONU Mujeres México indican que esta proporción en 2016 fue de 59\% (La violencia feminicida en México, aproximaciones y tendencias 1985-2016). 
cológico, físico, patrimonial, económico, sexual o la muerte tanto en el ámbito privado como en el público" (Ley General, art. 5o., fracción IV).

Efectivamente, la ineficiencia del aparato del Estado para imponer las sanciones previstas en su normatividad por las instituciones de justicia desde la policía investigadora hasta la Suprema Corte de Justicia de la Nación (SCJN), opera como una educación en sentido inverso que puede ser definida como la socialización de la impunidad.

Lo mismo puede decirse de las políticas públicas preventivas. La mayoría de ellas, referidas a prevención de la violencia contra las mujeres, se enfocan a la construcción de instrucciones (protocolos) dirigidos a las mujeres y niñas sobre medidas que deberían ser eficientes para evitar la violencia en su contra; las llamadas políticas de atención a víctimas son un listado de lo que tiene que hacer la propia mujer o niña que es víctima después de haber vivido el hecho violento ante cada autoridad. ${ }^{4}$

El proceso de esta socialización funciona, en el macrocosmos social, exactamente igual como funciona en el microcosmos familiar. En este sentido, lo público y lo privado se dan la mano y se asemejan porque, cuando una regla se incumple sistemáticamente y la sanción prevista por la autoridad no llega (autoridad, llámese: papá, mamá, sacerdote, rabino, policía o juez), los valores se trastocan y se fortalece la cultura del "al fin y al cabo, aquí no pasa nada"; se socializa, como señalé hace un momento, la impunidad; se fortalece una cultura en la que las normas no son importantes y priva la ley del más fuerte; ahí en donde, la sistemática inoperatividad de la justicia impide también la reparación del daño y, algo más grave, la construcción y consolidación de la ciudadanía.

En otras palabras, la impunidad fortalece un tipo de cultura en la que conceptos como el de ciudadanía y bien común no tienen cabida; una cultura - o anticultura - que se opone a los conceptos de respeto, dignidad, libertad para hacer valer la ley del más fuerte.

4 A partir del 2007 el Instituto Nacional de las Mujeres ha promovido en las entidades federativas de nuestro país la creación de protocolos de prevención, atención o sanción de la violencia contra las mujeres; hay ya una cantidad importante de ellos, como se puede constatar en el Centro de Documentación de este Instituto o en la Comisión Nacional para Prevenir y Erradicar la Violencia Contra las Mujeres, en donde, por ejemplo, se encuentra el Protocolo para la Prevención, atención y sanción del hostigamiento sexual y acoso sexual en la administración pública federal, del 9 de noviembre de 2016. Me refiero a la mayoría porque sería demasiado largo nombrar a cada uno, en mi opinión. 
Corresponde al Estado tener políticas públicas que aseguren sistemas de procuración y administración de justicia eficientes de tal suerte que las normas cumplan con su función de control y garanticen eso que andamos buscando: la multicitada seguridad. Cuando el aparato del Estado no persigue las conductas antisociales y los delitos, cuando permite que la impunidad se convierta en una constante social, no sólo se hace cómplice de ellos, sino que es cómplice de la socialización de la violencia, de los agravantes de la violencia y de la inseguridad.

Patricia Duarte y Gerardo González (1995) señalan, con razón, que, en el marco del pacto social, la búsqueda de la justicia y la lucha contra la impunidad son una cuestión de orden, democracia, ciudadanía y sentido social. A ello, es preciso añadir que para las mujeres es cuestión de sobrevivencia, simple y llanamente. Por tanto, la medición debe ser no sólo numérica, debe abarcar la percepción misma de la experiencia de la justicia o de la otra cara de la moneda: impunidad.

Sin embargo, tanto la percepción como la experiencia se insertan en una serie de principios calificados como jurídicos que han prevalecido en nuestros sistemas normativos y de justicia sin ser cuestionados: la igualdad de las personas ante la ley - entendida en el sentido de idéntico- y la neutralidad de la norma jurídica.

Dos supuestos a los que identifico como parte de los obstáculos que enfrentamos en la construcción de una democracia sustentada y arraigada en la ciudadanía; entendida ésta como un sentido de pertenencia a una comunidad a la que tengo derecho de exigir justicia y que ésta me sea dada; a la que tengo derecho de exigir protección y con la cual tengo derecho de interactuar para que se construya y estructure de manera en que la regla de oro contenga los principios que ya señalé: igualdad, no discriminación, respeto por la dignidad y la libertad de las personas y si esta regla no se cumple, justicia y reparación del daño.

En realidad el binomio de la igualdad jurídica formal y la neutralidad de la ley, oculta el carácter clasista y patriarcal de nuestro sistema jurídico, porque obliga a hacer tabla rasa ahí donde hay enormes diferencias marcadas por enormes inequidades que son históricas y parecen formar irremediablemente parte de las vidas de las mujeres agravadas por sus propias condiciones como el color de la piel, su clase social, el idioma o lengua en el que se expresan, la religión que profesan, las decisiones que hayan tomado sobre su sexualidad y sobre su capacidad reproductiva, su nacio- 
nalidad, si son migrantes o están establecidas en un lugar determinado, y el largo etcétera que define la diversidad en el vocablo mujeres.

Vale la pena retomar las expresiones de una comunidad indígena " $\mathrm{La}$ ley es la que dice que se haga justicia por la persona, pero ¿será que hay una ley con los ricos y aparte es una ley con los indígenas?" (Luisa Cabrera, 2001, p. 37). Expresiones que se pueden parafrasear: ¿una ley para las mujeres y otra para los hombres?

Es cierto que no podemos pretender que la sola disposición normativa restituya un equilibrio que un sinfín de factores culturales, económicos y sociales obstaculiza; tampoco podemos pretender que la aplicación de esa disposición normativa puede ser neutra porque la sociedad no es neutra, porque mujeres y hombres no somos neutros, nuestras acciones tampoco lo son. Por tanto, la generalidad y neutralidad de la norma son principios que deben ser cuestionados y analizados a partir de la realidad que se impone: existe una diversidad de seres humanos con necesidades específicas y la normatividad no necesariamente reconoce esa diversidad y esas necesidades múltiples.

Sin embargo, sabemos - o intuimos - que sólo entendiendo a las mujeres y a los hombres como parte de todo un sistema de relaciones - poder, sumisión, opresión, solidaridad, ayuda, compromiso- que se mueven en el ámbito público y en el privado; en la pareja, en la familia, en el grupo y en la sociedad; que interactúan en un contexto histórico bajo valores y creencias que no necesariamente han sido repensadas y replanteadas, sólo así - pensando en este cosmos construido de una pluralidad de cosmos - se puede hablar de justicia en el sentido más amplio y apropiado para todas las personas.

Lo sabemos - o lo intuimos-, pero todavía no podemos dar el paso definitivo para plasmar en la norma esa igualdad de oportunidades ante las diferencias reales; no podemos convencernos de que la neutralidad de la ley es una forma de discriminación por omisión, por ignorancia o por prepotencia.

La impunidad de los actos de violencia contra las mujeres tiene una connotación importante de discriminación (ONU, 1992) de género precisamente porque las estructuras jurídicas tienen como base la supuesta neutralidad de la norma y la concomitante imparcialidad de jueces y magistrados, con lo cual se desconoce una realidad: no sólo la violencia contra las mujeres no es neutra y sí es un acto de abuso de poder, sino 
que las personas que trabajan e interactúan en los espacios de procuración y administración de justicia forman parte de la sociedad que permite, tolera y regenera esa violencia, con valores que privilegian lo económico y el poder sobre la vida y la seguridad, sobre el respeto y la solidaridad.

Es decir, estamos frente a una estructura de control y represión insensible a la forma de funcionar de la violencia contra las mujeres y, por lo tanto, incapaz de reconocer los actos punibles y sancionarlos, lo que se traduce en inseguridad creciente para las mujeres.

En este sentido, hablando del objetivo de la justicia de hacer los equilibrios necesarios frente a la violencia que se tolera a partir de esos controles y represiones de las estructuras sociales, se afirma que:

El procesamiento judicial sería una forma de afrontar el trauma ocasionado por la violencia; en este sentido se convierte en una forma de resistencia activa y colectiva. Pero la impunidad tejida para impedir la justicia convierte esta lucha por la vida en una prolongación de la violencia y, por tanto, en la re-experimentación del trauma originalmente sufrido (Luisa Cabrera, 2001, p. 39).

En el espacio en donde se reconoce "al ciudadano", ${ }^{5}$ al que está involucrado en el quehacer común, el quehacer político y la seguridad, esto es en el ámbito público, las categorías demográficas del sexo o la edad, no son relevantes, por tanto, no se contemplan o no son escuchadas, de ahí que las tasas de impunidad de los delitos cometidos en contra de mujeres e infantes sean más altas que en otros como los delitos patrimoniales; tasas de impunidad que corresponden a las políticas públicas y a las convicciones sociales definidas en las propias normas penales. ¿Qué pensar, pues, del alcance de la impunidad que cuestiona una y otra vez, el sentido de las leyes y de la propia justicia? ¿Qué pensar de la reiterada, repetitiva, permanente, impunidad de los actos de violencia contra las mujeres? Impunidad legal, política, social. ¿Es necesario consignar los porcentajes comparativos o basta escuchar a las mujeres víctimas, a los reclamos socia-

5 El uso del genérico masculino no responde a la regla gramatical que indica que éste incluye a las mujeres, hago referencia, de manera exclusiva a los hombres, es decir, al género masculino de la especie humana. 
les constantes cada 8 de marzo y 25 de noviembre, por lo menos, en este país? ${ }^{6}$

Recordemos dos detalles: hasta hace no mucho tiempo, finales del siglo XX, en nuestro país el robo de una vaca era más sancionado que la violación de una mujer en casi todas las entidades federativas, por no decir en todas (Alicia Elena Pérez Duarte y Noroña y Laura Salinas, 1997); hoy sucede lo mismo en varias entidades federativas, con el hostigamiento sexual o la violencia familiar frente al robo de autos, al robo o traslado de más de diez vacas, caballos o mulas o la extorsión. ${ }^{7}$

Los candados para la integración de los cuadernos de investigación, los requisitos de las pruebas, los manuales de procedimientos insensibles a la categorías edad y sexo, hacen que las puertas de la justicia estén prácticamente clausuradas para las mujeres y niñas víctimas de actos de violencia contra las mujeres, como si existieran hilos invisibles que manejan la justicia, los registros y el seguimiento de los casos, de tal manera que es fácil distorsionar la justicia en los casos de violencia contra las mujeres. ${ }^{8}$

¿Cómo resolver este problema? Desde luego, los primeros pasos se han dado desde hace ya varios de lustros en todo nuestro país: hacer visible la violencia contra las mujeres. Es cierto que el trabajo realizado ha sido casi todo enfocado a la violencia en el ámbito familiar y hacia un tipo de violencia: la sexual, descuidando otras modalidades como la existente en instituciones, en las comunidades, en el trabajo y las escuelas, o pretendiendo confusiones frente a los diversos tipos de violencia como el patrimonial, económico, psicológico.

6 Baste referir que, en el Diagnóstico nacional sobre todas las formas de violencia contra las mujeres, realizado por la Facultad de Derecho de la Universidad Nacional Autónoma de México por encargo de la Secretaría de Gobernación (2009), se ponen en evidencia que el denominador común de los actos de esta violencia es su falta de registro y seguimiento, a pesar de que la normatividad lo exige.

7 Sólo por citar algunos ejemplos, esta afirmación se puede constatar en los códigos penales de Guanajuato, San Luis Potosí, Sonora y Sinaloa en donde el abigeato o robo de ganado merece de dos a 10 años de prisión y el hostigamiento o acoso sexual de dos meses a dos años.

8 Luisa Cabrera (2001) utiliza esta imagen para las violaciones a los derechos humanos de las mujeres en Guatemala que es válida también para el caso de México en el tema de la violencia de género contra las mujeres. Ejemplos de impunidad tenemos miles, desde los que simplemente no llegan a las autoridades hasta casos emblemáticos como el de Marisela Escobedo Ortiz y de su hija Rubí Marisol.

Esta obra está bajo una Licencia Creative Commons

Atribución-NoComercial-SinDerivar 4.0 Internacional, IIJ-UNAM.

Boletín Mexicano de Derecho Comparado, núm. 160, enero-abril de 2021, pp. 335-359. 
Sí, es cierto, pero, lo hemos logrado, a partir de $2007^{9}$ hemos avanzado, a pesar de todo y muchas veces contra todos, lo hemos hecho. Hoy se habla y discute el tema y se buscan formas y modelos de prevenir, atender, sancionar y erradicar este problema que ya nadie se atreve a calificar públicamente como normal; se destinaron recursos económicos importantes para diseñar políticas públicas adecuadas y pensar en reestructurar los espacios de procuración y administración de justicia desde la base, desde ahí en donde se genera la ciencia del derecho y se forman las personas que han de actuar en dichos espacios, para tratar de remover los obstáculos que impiden el acceso de las mujeres a la justicia y a la reparación del daño, ocultando, además, sus dimensiones en un manto de reglas sobre supuesta discreción en aras de "derechos humanos" de las personas procesadas. También hay decisiones emblemáticas que generan esperanza, algunas arrancadas a fuerza de manifestaciones, pero ahí están, como es la decisión de la SCJN por la que la investigación de la muerte violenta de Mariana Lima Buendía fuera llevada bajo la hipótesis el feminicidio (Amparo en revisión 554/2013; véase también Karla I. Quintana, 2018).

\section{LA PERCEPCIÓN SOCIAL SOBRE LA IMPUNIDAD}

En el marco de los trabajos que desarrolló la Comisión Especial del Senado para dar Seguimiento a las Investigaciones de los Asesinatos de mujeres en Ciudad Juárez, Chihuahua, durante la LIX Legislatura (2005) se realizó un cuadro comparativo entre el programa del gobierno federal para atender la problemática que se vive en esa ciudad fronteriza, conocido como el Programa de 40 puntos, y las recomendaciones de organismos intergubernamentales y no gubernamentales internacionales para atender este caso paradigmático de violencia contra las mujeres y de los efectos de una sistemática impunidad.

En este documento se observa cómo, si bien cada organismo, según su vocación, hace énfasis en cierto tipo de medidas, todos coinciden en dos necesidades fundamentales: contar con un marco jurídico apropiado para evitar la impunidad y el fortalecimiento de capacidades del funcionariado

9 Señalo este año por ser el de la promulgación de la Ley General. Independientemente, desde luego, de que hoy se señala que esta ley ha seguido el mismo camino de otras en su tipo: el de la ineficacia. Por tanto, no ha sido suficiente para combatir la impunidad. 
público encargado de la procuración y administración de justicia ${ }^{10}$ pues es evidente que, hasta ahora, la perspectiva de género es una materia pendiente, en estas tareas fundamentales para evitar la impunidad de los actos de violencia contra las mujeres, a pesar de los años ya transcurridos desde la publicación de protocolos de actuación con perspectiva de género, tanto en el Poder Judicial federal como en los locales y en los ministerios públicos. ${ }^{11}$

Hoy estamos en el momento en que podemos reflexionar de manera conjunta en el significado de la impunidad de los actos de violencia contra las mujeres; sobre las diferencias entre la percepción social y los datos duros; explicar las razones de la percepción generalizada que señala la disfuncionalidad - por no decir inutilidad - de los sistemas de justicia, tanto como señalar y delimitar con claridad las responsabilidades sobre esa percepción social.

Sería conveniente recordar que precisamente en el ámbito internacional se han adoptado una serie de recomendaciones para combatir la impunidad tanto la general como la relativa a la violencia contra las mujeres y que, en los términos de la Ley General y su reglamento, perfilan un verdadero modelo de sanción que permite dimensionar la impunidad de manera que se entiendan sus causas y consecuencias.

Es decir, un modelo que atiende los requerimientos de un sistema jurídico por medio de evaluaciones permanentes y sistemáticas sobre la aplicación de esta ley y de las diversas normas jurídicas que regulan los tipos y modalidades de la violencia, que debe contener como mínimo:

- Las directrices de apoyo para las y los servidores públicos que conozcan de los tipos y modalidades de violencia contemplados en la Ley, para facilitar su actuación en la aplicación de sanciones conforme a la legislación aplicable que corresponda.

- Las medidas de atención y rehabilitación para los agresores.

10 En lenguaje de aquel entonces, hoy se diría encargado a las y los operadores del sistema de justicia penal, en especial a quienes tienen a su cargo la investigación de los delitos.

11 Es el caso, por ejemplo, del Protocolo para Fuzgar con Perspectiva de Género (SCJN, 2013); Cuaderno de buenas prácticas para juzgar con perspectiva de género (Ana Elena Fierro y Adriana García, 2014); Protocolo para la atención de personas que han sufrido el delito de violación, entre muchos otros (Secretaría de Seguridad Pública, 2009).

Esta obra está bajo una Licencia Creative Commons

Atribución-NoComercial-SinDerivar 4.0 Internacional, IIJ-UNAM.

Boletín Mexicano de Derecho Comparado, núm. 160, enero-abril de 2021, pp. 335-359. 
- La capacitación especial necesaria para la aplicación del Modelo de Sanción dirigida al personal que integran las corporaciones de seguridad pública y del sistema de procuración y administración de justicia.

- Los mecanismos de notificación al órgano de fiscalización correspondiente, para el caso de incumplimiento de la Ley o el Reglamento por parte de los servidores públicos.

- Los lineamientos que faciliten a la víctima demandar la reparación del daño u otros medios de compensación o resarcimiento económico a cargo del agresor, en términos de la legislación aplicable.

- Los indicadores de factores de riesgo para la seguridad de la víctima tales como los antecedentes violentos del agresor o el incumplimiento de las órdenes de protección de éste, entre otros.

- Las prevenciones necesarias para evitar que las mujeres que han sufrido violencia vuelvan a ser víctimas de ésta, y

- Los lineamientos que faciliten a la víctima demandar una reparación del daño u otros medios de compensación o resarcimiento económico a cargo del Estado, cuando haya responsabilidad de éste, en términos de la legislación aplicable.

Requerimientos que surgen de una serie de recomendaciones internacionales que puede ser clasificada en dos grupos: el primero de estos grupos lo constituyen las recomendaciones generales emanadas de las comisiones orgánicas de Naciones Unidas o de la Organización de los Estados Americanos, el segundo, las recomendaciones particulares hechas a nuestro país por órganos de vigilancia y control de los derechos humanos, ya sea contractuales o no contractuales.

Sin embargo, basta una pequeña ojeada a las redes para encontrar palpable el descontento social por la impunidad que impera en nuestro país sobre las violencias contra las mujeres.

Dos organizaciones del Observatorio Nacional sobre Feminicidio, en 2012, presentaron al Comité de la Convención para la Eliminación de todas las Formas de Discriminación contra la Mujer (en adelante CEDAW por sus siglas en inglés), un informe sobre feminicidio e impunidad en México (Católicas por el Derecho a Decidir y Comisión Mexicana de Defensa y Promoción de los Derechos Humanos, 2012) en el que se 
resume que los mecanismos legales existentes no garantizan la protección a la vida y la integridad de las mujeres en el país; que ocupamos el lugar 16 en la incidencia de homicidios contra mujeres a nivel mundial; que estos homicidios han registrado un aumento sostenido desde 2007, año que se registró el menor número de feminicidios desde 1985; que existe un patrón de impunidad sistémica, reflejo de la falta de acceso a la justicia para las mujeres; que con frecuencia las víctimas, al intentar acceder al sistema de justicia, son maltratadas y discriminadas; que la mayoría de los casos de violencia contra las mujeres no son investigados como es debido ni juzgados ni sancionados por el sistema de justicia tanto federal como de las entidades federativas.

Se señala que en el país se observa una resistencia considerable para investigar los asesinatos de mujeres como feminicidio; ${ }^{12}$ que es común que cuando existe una muerte violenta de mujer se afirme en primer lugar que se trata de suicidio; ${ }^{13}$ que $97 \%$ de los actos de violencia contra las mujeres quedan en la impunidad. Todo ello, según se puede concluir tanto de las referencias en las redes sociales como de las cada vez más numerosas manifestaciones de protesta que se dan en el país, es percibido como el desconocimiento de la perspectiva de género en las instituciones públicas, así como la falta de voluntad política de los órganos del Estado para prevenir y sancionar la violencia feminicida.

\section{CONCEPTO DE IMPUNIDAD EN EL ÁMBITO INTERNACIONAL}

El primer acercamiento normativo a la lucha contra la impunidad tiene su fundamento, en el ámbito internacional, en la Declaración Universal de los Derechos Humanos y en el Pacto Internacional de los Derechos Civiles y Políticos. Ambos instrumentos contemplan como parte del catálo-

12 El Observatorio Ciudadano Nacional del Feminicidio (2018) afirma que entre 2014 y 2017 fueron asesinadas un total de 8904 mujeres, sólo 2188 casos fueron investigados como feminicidios. Consultable en https://92eab0f5-8dd4-485d-a54f-b06fa499694d.filesusr. com/ugd/ba8440_66cc5ce03ac34b7da8670c37037aae9c.pdf

13 Como ejemplo de ello es los casos emblemáticos del feminicidio de Mariana Lima Buendía (véase Amparo en revisión 554/2013) y de Lesvy Berlín Rivera Osorio (Recomendación 01/2018 de la CDHDF. Caso: Falta de debida diligencia reforzada en la investigación del posible feminicidio de Lesvy Berlín Rivera Osorio, y negligencia en la atención a sus familiares).

Esta obra está bajo una Licencia Creative Commons

Atribución-NoComercial-SinDerivar 4.0 Internacional, IIJ-UNAM.

Boletín Mexicano de Derecho Comparado, núm. 160, enero-abril de 2021, pp. 335-359. 
go de los derechos humanos el acceso a una justicia pronta y completa, tal como se recoge, también, en la Constitución federal de nuestro país. ${ }^{14}$

La ubicación de este derecho, en el ámbito de la lucha por prevenir, sancionar y erradicar la violencia contra las mujeres tiene su fundamento en la Convención Interamericana que lleva ese nombre y se conoce como Convención do Belém do Pará, de la cual México es parte, en donde, aunque no se hace explícito el concepto de impunidad, se definen medidas concretas para combatirla, y proteger a las mujeres víctimas de violencia, estén donde estén.

La Subcomisión de Prevención de Discriminaciones y Protección de las Minorías, ${ }^{15}$ en 1997, realizó dos estudios relacionados con la impunidad de los autores de las violaciones de los derechos humanos relativos a los derechos civiles y políticos. Trabajo que es aplicable, en toda su extensión al tema de la violencia contra las mujeres, precisamente porque entre los derechos civiles y políticos se encuentran el derecho a la vida, a la seguridad personal y el derecho al acceso a la justicia, tres de los cuales son sistemáticamente violados cuando una mujer que ha sido víctima de violencia no puede obtener la reparación que le es debida. Expertos de ese órgano, señalan que la impunidad viola (Louis Joinet, 1997), por el sólo hecho de existir, tres tipos de derechos que tienen alcances tanto individuales como colectivos: el derecho a saber, a la justicia, y a la obtención

14 Es a propósito que elimino el concepto de imparcialidad como característica de la justicia pues esta presunta imparcialidad ha hecho mucho daño a la causa de las mujeres, aunque es cierto que se trata de una característica consagrada en nuestra la Constitución y, durante mucho tiempo, fue la piedra de toque de la justicia porque se tuvo que hacer un contrapeso a la parcialidad que existía al inicio del surgimiento del Estado de derecho. Hoy, esa imparcialidad está haciendo mucho daño a la causa de las mujeres precisamente porque no se reconoce la realidad de sus desventajas ni la discriminación que padece, y así lo dicen los expertos internacionales con quienes coincido plenamente (véase Ana Messuti, 2008).

15 Fue establecida por la Comisión de Derechos Humanos de Naciones Unidas en su primera sesión, en 1947, bajo la autoridad del Consejo Económico y Social, como el principal órgano consultivo en esta materia. Conforme a la decisión del 27 de julio de 1999 del Consejo Económico y Social, el nombre de la Subcomisión de Prevención de Discriminaciones y Protección a las Minorías se ha cambiado a Subcomisión para la Promoción y Protección de los Derechos Humanos. Actualmente este órgano fue sustituido por el Comité Asesor del Consejo de Derechos Humanos mediante resolución del propio Consejo 5/1. Funciona como "grupo de reflexión” y trabaja, como lo hacía la Subcomisión, bajo la dirección del multicitado Consejo. 
de una reparación, independientemente de los derechos que son violentados por el delito que queda sin sanción.

El derecho a saber, en lo individual, comprende el derecho que asiste a toda víctima o sus familiares de conocer de manera verídica lo que ocurrió, por muy doloroso que ello sea; en lo colectivo este derecho "hunde sus raíces en la historia, para evitar que puedan reproducirse en el futuro las mismas violaciones", por tanto, al Estado "le incumbe el deber de recordar".

El derecho a la justicia, en lo individual, implica, que toda víctima o sus familiares deben tener la posibilidad de hacer valer sus derechos beneficiándose de un recurso equitativo y efectivo, de tal suerte que quien violentó sus derechos sea juzgado y, al mismo tiempo, obtenga una reparación por todos los daños y perjuicios sufridos.

En lo colectivo, estos derechos, a la justicia y a la reparación, son piedra fundamental en el cumplimiento de los fines de un Estado democrático de derecho, pues comprende medidas de cuyo carácter simbólico da fuerza y cohesión a las instituciones llamadas democráticas.

Estos conceptos han sido recogidos en un documento conocido como Principios para la protección de los derechos humanos mediante la lucha contra la impunidad, en el cual se define a la impunidad como

...la inexistencia, de hecho o de derecho, de responsabilidad penal por parte de los autores de violaciones de los derechos humanos, así como de responsabilidad civil, administrativa o disciplinaria, porque escapan a toda investigación con miras a su inculpación, detención, procesamiento y, en caso de ser reconocidos culpables, condena, incluso a la indemnización del daño causado a sus víctimas.

Concepto que se puede aplicar de manera directa a la inexistencia de la responsabilidad penal por actos de violencia contra las mujeres.

Por su parte, la Comisión de Naciones Unidas para la prevención del Delito y la Justicia Penal ha trabajado el tema de la impunidad por medio de los conceptos de prevención del delito y de los derechos de las víctimas. Desde 1985 aprobó un documento denominado 'Declaración sobre los principios fundamentales de justicia para las víctimas del delito y del 
abuso de poder", ${ }^{16}$ en el cual se definen los derechos de las víctimas a la justicia y a la reparación del daño.

En el manual elaborado para la aplicación de estos principios, se indica que las medidas para combatir la impunidad y para perseguir a los criminales son, al mismo tiempo, el "sine qua non de la justicia" y "la correcta reparación a las víctimas".

Otro documento importante en el combate a la impunidad que fue producto de los trabajos de esa comisión orgánica son las Medidas de prevención del delito y de justicia penal para la eliminación de la violencia contra la mujer. ${ }^{17}$ En estas medidas, entre otras recomendaciones, se reitera la necesidad de revisar, evaluar y enmendar periódicamente las leyes, códigos y procedimientos nacionales "para cerciorarse de su utilidad y eficacia en lo que respecta a la eliminación de la violencia contra la mujer y supriman toda disposición que permita o condone la violencia contra la mujer". ${ }^{18}$

\section{LAS RECOMENDACIONES DE LOS ÓRGANOS DE CONTROL Y VIGILANCIA DE LOS DEREGHOS HUMANOS}

El Comité para la Eliminación de Todas las Formas de Discriminación en Contra de la Mujer, órgano de vigilancia de la Convención del mismo nombre, elaboró una recomendación específica $(\mathrm{ONU}, 1992)^{19}$ sobre la violencia contra las mujeres en la cual señala de manera puntual la obligación que tienen los Estados partes de la CEDAW de adoptar medidas apropiadas y eficaces para combatir todo tipo de violencia basada en el sexo, ejercida mediante actos públicos o privados y de velar por que las leyes contra la violencia y los malos tratos en la familia, la violación, los ataques sexuales y otro tipo de violencia contra la mujer protejan de manera adecuada a todas las mujeres y respeten su integridad y dignidad.

16 Aprobados por Asamblea General de Naciones Unidas en la resolución 40/34, del 29 de noviembre de 1985. Ver anexos.

17 Aprobadas por la Asamblea General de Naciones Unidas en su resolución 52/86 de 1998 (Documento A/RES/52/86, 1998).

18 Ibidem, p. 5.

19 Recomendación 19 del CEDAW, actualizada en 2015 con la Recomendación 35 sobre la violencia por razón de género contra la mujer del mismo Comité. 
Desde luego, estas dos medidas deben ir acompañadas de una adecuada capacitación al funcionariado encargado de los órganos de justicia a fin de que el derecho de las mujeres a una vida libre de violencia sea efectivo y que las violaciones a este derecho sean debidamente sancionadas, así como de procedimientos eficaces de denuncia y reparación, incluida la indemnización por los daños y perjuicios sufridos y de las medidas necesarias para dar protección inmediata a las mujeres víctimas de violencia sea esta familiar o extra familiar.

En la Recomendación 35 de este Comité, se señala que "la opinio juris y la práctica de los Estados dan a entender que la prohibición de la violencia por razón de género contra la mujer ha pasado a ser un principio del derecho internacional consuetudinario" (CEDAW/C/GC/35, 2017, párrafo 2); sin embargo, se afirma que sigue siendo generalizada en todos los países y, sobre todo, con un alto grado de impunidad. Se pone sobre la mesa un tema preocupante y vigente en México: la reducción "significativa" del gasto público destinado la prevención y la judicialización de los actos de violencia contra las mujeres, "a menudo como parte de las denominadas medidas de austeridad tras las crisis económicas y financieras, contribuyen a debilitar todavía más las respuestas de los Estados" (CEDAW/GC/35, 2017, párrafo 7) realidad tristemente dolorosa en este aciago 2020.

Este Comité, en las tres últimas revisiones de informes periódicos de México ${ }^{20}$ solicitó que se proporcionara información sobre los mecanismos que existen para que las mujeres puedan apelar judicialmente con base en la Convención, y recomendó que se aplicara en el país la Recomendación General 19, que ahora debe ir actualizada por la número 35 ya citada.

Por otra parte, el Comité de Derechos Humanos, en la evaluación del quinto Informe periódico del gobierno de México, ${ }^{21}$ manifestó una preocupación - basada tanto en el derecho a la seguridad e integridad personal como en el derecho al acceso a la justicia - por el nivel de violencia

20 El 17 de mayo de 2011 , el gobierno de México presentó al CEDAW el sexto informe periódico el 23 de enero de 2006 (Documento CEDAW/C/MEX/6), los informes séptimo y octavo consolidados en donde abarca el periodo agosto 2006-septiembre 2010 (Documento CEDAW/C/MEX/7-8) y el noveno informe periódico el 2 de febrero de 2017 (Documento CEDAW/C/MEX/9).

21 Véase Documento de Naciones Unidas CGPR/C/MEX/5, 2008.

Esta obra está bajo una Licencia Creative Commons

Atribución-NoComercial-SinDerivar 4.0 Internacional, IIJ-UNAM.

Boletín Mexicano de Derecho Comparado, núm. 160, enero-abril de 2021, pp. 335-359. 
que existe en el país contra las mujeres, incluyendo los muchos casos denunciados de secuestro y asesinato que no han conducido a arrestos o procesamiento de los culpables, y las numerosas quejas de violación o tortura perpetradas por las fuerzas de seguridad a las mujeres detenidas, que éstas no se atreven a denunciar y recomendó que se tomaran medidas eficaces para garantizar la seguridad de las mujeres y para asegurar que no se ejerza ninguna presión sobre ellas con el fin de disuadirlas de denunciar tales violaciones y asegurar que todas las quejas de abusos sean investigadas y que los autores de estos actos sean llevados ante la justicia.

Por su parte el Comité de Derechos Económicos, Sociales y Culturales en el examen del tercer informe periódico de México, desatacó la necesidad de combatir las causas que originan la violencia contra las mujeres, entre las que se encuentra la impunidad.

En mayo del 2001, el relator especial sobre la independencia de abogados, jueces y magistrados estuvo en México en visita oficial. Este funcionario afirmó que era necesario tomar una serie de medidas para que las mujeres víctimas de violencia tuvieran acceso a los medios de procuración y administración de justicia, entre estas medidas señaló que se debería dar formación especial a la policía y los agentes del Ministerio Público quienes han de recibir formación sobre la forma de tratar a las víctimas de la violencia sexual y examinar la posibilidad de establecer unidades especiales que se ocupen de los delitos de violencia contra las mujeres. ${ }^{22}$ Esta recomendación se repitió diez años después cuando la entonces Relatora Especial en esta misma materia, visitó a México. ${ }^{23}$

Durante la segunda semana de febrero del 2007, el gobierno de México se presentó ante el Examen Periódico Universal sobre la situación de los derechos humanos en el país ante el Consejo de Derechos Humanos. ${ }^{24}$ Tema obligado fue precisamente la impunidad en materia de vio-

22 El relator especial fue Dato'Param Coomaraswamy; la misión se llevó a cabo del 13 al 23 de mayo de 2001. Véase el informe en el Documento de Naciones Unidas E/ CN.4/2002/72/Add.1 (2002).

23 Esta misión oficial se llevó a cabo del 1o. al 15 de octubre de 2010. En esta ocasión la relatora especial fue la señora Gabriela Carina Knaul de Alburquerque y Silva. Véase el informe en el Documento de Naciones Unidas A/HRG/17/30/Add (2011).

24 Este Consejo es un órgano intergubernamental creado en el marco del sistema de las Naciones Unidas, en sesión del 15 de marzo de 2006, de la Asamblea General de las Naciones Unidas. Está compuesto por 47 Estados miembros responsables del fortalecimiento 
lencia contra las mujeres: Ciudad Juárez, Atenco, Lydia Cacho, casos emblemáticos en el país que subrayan la necesidad de dimensionar y atender de manera diferente, sin discriminación, a las mujeres que buscan atención, apoyo y justicia, fueron temas que estuvieron en la agenda de trabajo (ONU, A/HRG/WG.6/4/MEX/1; A/HRG/WG.6/4/MEX/2; A/ HRC/WG.6/4/MEX/3). ${ }^{25}$

En el informe presentado por el gobierno de México, se reconoce que el sistema de justicia debe depurarse y se pretende justificar - o explicar- el porqué del disfuncionamiento de nuestros espacios de procuración y administración de justicia que son causa, origen y razón de la dimensión de la impunidad en cualquier materia, pero aún más en esta que nos ocupa.

Desde luego, las recomendaciones ahí están. Dos muy importantes, la primera en materia de armonización legislativa, precisamente para revertir y corregir el disfuncionamiento a que se hacer referencia en el párrafo anterior y el trabajo para la erradicación de la violencia contra las mujeres que implica un esfuerzo en el que se conjugan los ejes de trabajo que nos unen en este momento: prevención, atención y sanción. Ejes que deben tener una base sólida de comprensión y dimensión del fenómeno (ONU, A/HRG/WG.6/4/L.13).

Cabe recordar, para concluir este punto, que el Comité de Derechos Humanos en julio de 2018 condenó a México por lo que calificó como un patrón de violencia sexual contra las mujeres detenidas en México, conductas que por lo general quedan impunes, al revisar el caso de la periodista Lydia Cacho que fue sometido a su consideración por primera vez por violencia contra las mujeres cometida por el Estado en contra de una mujer periodista.

de la promoción y la protección de los derechos humanos en el mundo. Uno de sus objetivos principales es el estudio de las situaciones de violaciones de los derechos humanos en los países y hacer recomendaciones en esta materia.

25 Es de recordar que el Comité de Derechos Humanos de Naciones Unidas condenó a México. 


\section{COLOFÓN A MANERA DE GONCLUSIONES}

La violencia contra las mujeres es un acto de abuso poder, similar a la tortura. Así ha sido reconocido por la Organización Mundial de la Salud pues, se señala, se trata de un abuso de poder en el cual las agresiones están destinadas a lesionar la salud psicológica de la mujer al igual que su cuerpo, y suelen ir acompañadas de humillación y violencia física. Estas agresiones son impredecibles y guardan poca relación con el comportamiento de las mujeres. El único dato significativo es que están bajo el poder de un hombre agresor.

A pesar de lo que digan; si una mujer, en su hogar, su trabajo, la escuela, la calle, tiene la desgracia de cruzar su camino con un agresor que desee ejercer este tipo de violencia para sentir su poder, será torturada, humillada, vejada, violada y, posiblemente, hasta asesinada, sin importar cómo se comporte o cómo esté vestida.

Lo menos que se puede pedir, es justicia y protección para la víctima y sus familiares. Justicia que va desde la sanción a los responsables del delito o de la conducta violenta, si se trata de violencia familiar no sancionada por la ley penal, hasta la sanción de las autoridades que, al incumplir con su tarea, permiten la impunidad y la reproducción de estas conductas que laceran la dignidad de las mujeres.

Protección que implica una nueva visión de todo el sistema de justicia en la cual se reconozca la desigualdad real que tiene una mujer frente a su agresor; una nueva visión que reconozca los factores ideológicos reflejados tanto en una norma jurídica como en una acto abusivo de poder; una nueva visión que impida a policías, ministerios públicos, jueces y magistrados, hacer tabla rasa de las diferencias entre las víctimas y los agresores; que no les permita pretender una igualdad donde no existe ni reproducir ideologías discriminatorias en contra de las mujeres víctimas; que no les permita exigir demostrar las circunstancias de tiempo, modo y lugar en situaciones que sabemos es imposible hacerlo.

La impunidad en general, la impunidad de los actos de violencia en contra de las mujeres, en lo particular, y la falta de reparación del daño, ${ }^{26}$ son elementos que juegan un papel medular como factor

26 Felipe Gómez Isa (2008) afirma que "La reparación a las víctimas de violaciones de los derechos humanos es otro de los elementos centrales de la lucha efectiva contra la im- 
de deterioro de la dignidad de las personas y del bienestar social e impide el ejercicio de la ciudadanía pues obstaculiza la capacidad que una persona tiene de perseguir a quien la ha agredido y para exigir que le sean restituidos sus derechos.

La violencia y el crimen medran cuando no existe igualdad, democracia, respeto por los derechos humanos y buen gobierno. El reto para acabar con la impunidad de la violencia contra las mujeres, ahí en donde se dé, es la reconstitución y el fortalecimiento del Estado de derecho dado que este concepto y la constitución de la ciudadanía están estrechamente vinculados con la concepción del ejercicio de los derechos y la seguridad para ejercerlos.

El trabajo para dimensionar la impunidad y luego erradicarla es la base de un modelo exitoso de sanción de la violencia contra las mujeres, cuyo contenido pasa por un marco jurídico adecuado, respetuoso de los derechos humanos, elaborado desde una perspectiva de género, formación de personal para los espacios de procuración y administración de justicia con esta visión y el reconocimiento de la propia problemática, pues es evidente que esta impunidad empieza porque en los espacios en donde se juzga y se procura la justicia no se cree que las mujeres digamos la verdad cuando denunciamos los actos de violencia en nuestra contra.

Parafraseando a Margherite Yourcenard (1985): posiblemente yo no crea como ellos creen, no viva como ellos viven, no ame como ellos aman, y si bien moriré como ellos mueren, en el camino, soy mujer, soy ciudadana y sé que junto a mi hay millones de mujeres que exigimos a una sola voz que afrontemos el reto de acabar con la impunidad de la violencia que se ejerce contra nosotras sólo por el hecho de ser mujeres y unamos nuestras energías para hacer una realidad el derecho a vivir una vida libre de violencia.

\footnotetext{
punidad. Debemos reconocer que en este ámbito se han producido avances considerables en los últimos años tanto a nivel universal como, sobre todo, en América Latina, como nos vamos a encargar de demostrar a continuación. En primer lugar, debemos subrayar que la reparación no es una panacea que va a solucionar todos los problemas relacionados con el pasado a los que se enfrentan las sociedades en transición. Ciertas secuelas de graves violaciones de derechos humanos son irreparables, tanto en su dimensión individual como colectiva; en ocasiones, las heridas son de tal naturaleza que a lo máximo a que se puede aspirar es a que las víctimas aprendan a vivir con ese dolor, ya que una total recuperación no es algo a lo que se pueda aspirar realistamente".
}

Esta obra está bajo una Licencia Creative Commons

Atribución-NoComercial-SinDerivar 4.0 Internacional, IIJ-UNAM.

Boletin Mexicano de Derecho Comparado, núm. 160, enero-abril de 2021, pp. 335-359. 


\section{BIBLIOGRAFÍA}

Amparo en revisión 554/2013. Primera Sala de la SCJN. 25/03/2015. Microsoft Word - CASO MARIANA LIMA.doc (fiscaliatabasco.gob.mx)

Cabrera, Luisa (2001). Efectos de la impunidad en el sentido de justicia. Psicología Política (23), pp. 37-58.

Católicas por el Derecho a Decidir (CDD) y Comisión Mexicana de Defensa y Promoción de los Derechos Humanos (CMDPDH) (2012). Feminicidio e impunidad en México: un contexto de violencia estructural y generalizada. GDD y CMDPDH.

Cobo, Rosa (1995). Fundamentos del patriarcado moderno. Jean Jaques Rousseau. Cátedra.

DuARTe SÁnchez, Patricia y GonzÁLez, Gerardo (1995). La lucha contra la violencia de género en México. De Nairobi a Beijing 1985-1995. COVAC.

Facultad de Derecho de la UNAM (2009). Diagnóstico nacional sobre todas las formas de violencia contra las mujeres.

Fierro Ferráez, Ana Elena y García García, Adriana (2014). Cuaderno de buenas prácticas para juzgar con perspectiva de género. Consejo de la Judicatura Federal.

FOUCAULT, Michel (1975). Surveiller et punir. Gallimard.

GÓmEz IsA, Felipe (2008). El fenómeno de la impunidad: luces y sombras. Pensamiento Iberoamericano (2): pp. 163-185.

Internacional Victimology Website. Manual de justicia sobre el uso y aplicación de la declaración de principios básicos de justicia para víctimas de delito y abuso de poder. 11/10/2020. http://wrere.worldsocietyofoictimology.org/publications/ Handbook\%20on\%20Justice\%20Sp.pdf

JOINET, Louis (1997). Informe final revisado acerca de la cuestión de la impunidad de los autores de violaciones de los derechos humanos (derechos civiles y políticos). Documento de Naciones Unidas E/CN.4/ Sub.2/1997/20/Rev.1. Del 2 de octubre de 1997. https://undocs.org/ es/E/CN.4/Sub.2/1997/20/Rev.1

INEGI (2016). Guarta Encuesta Nacional sobre la Dinámica de las Relaciones en los Hogares. https://www.inegi.org. $\mathrm{mx} / \mathrm{rnm} /$ index.php/cata$\log / 286$

Messuti, Ana (2008). La justicia deconstruida. Bellaterra. 
Naciones Unidas (1985). Declaración sobre los principios fundamentales de justicia para las víctimas del delito y del abuso de poder. https://wwre.ohchrorg/sp/professionalinterest/pages/victimsofcrimeandabuseofpower.aspx

Naciones Unidas (2005). Informe del Secretario General. Un concepto más amplio de la libertad: desarrollo, seguridady derechos humanos para todos. Documento de la Asamblea General A/59/2005.

Naciones Unidas (2009). Informe nacional presentado de conformidad con el párrafo 15 a) anexo a la resolución 5/1 del consejo de derechos humanos. Documento de Naciones Unidas A/HRC/WG.6/4/ $\mathrm{MEX} / 1$.

Naciones Unidas (1998). Medidas de prevención del delito y de justicia penal para la eliminación de la violencia contra la mujer. Aprobadas por la Asamblea General de Naciones Unidas en su resolución 52/86. Documento A/RES/52/86.

Naciones Unidas (1992). Recomendación General 19 del Comité para la Eliminación de Todas las Formas de Discriminación en Contra de la Mujer. Documento de Naciones Unidas A/47/38.

Naciones Unidas (2008). Recopilación preparada por la oficina del alto comisionado para los derechos humanos con arreglo al párrafo $15 \mathrm{~b}$ ) del anexo de la resolución 5/1 del Consejo de Derechos Humanos. Documento de Naciones Unidas A/HRG/WG.6/4/MEX/2.

Naciones Unidas (2008). Recopilación preparada por la Oficina del Alto Comisionado para los Derechos Humanos con arreglo al párrafo 15 b) del anexo de la resolución 5/1 del Consejo de Derechos Humanos. Documento de Naciones Unidas A/HRC/WG.6/4/L.13.

El Observatorio Ciudadano Nacional del Feminicidio (2018). Informe Implementación del Tipo Penal de Feminicidio en México: Desafios para Acreditar las Razones de Género 2014-2017. Católicas por el Derecho a Decidir. https://92eab0f5-8dd4-485d-a54f-b06fa499694d.filesusr.com/ugd/ba8440 _66cc5ce03ac34b7da8670c37037aae9c.pdf

Organización Mundial de la Salud (2013a). Global and regional estimates of violence against women. Prevalence and health effects of intimate partner violence and nonpartner sexual violence. https://apps.who.int/iris/handle/10665/85239

Organización Mundial de la Salud (2011). Prevención de la violencia sexual y violencia infligida por la pareja contra las mujeres. Qué hacer y cómo obtener evidencias. Organización Panamericana de la Salud. 
Organización Mundial de la Salud (2013b). Violence against women. The health sector responds. https://apps.who.int/iris/handle/10665/87060

PÉrez DuARTe y Noroña, Alicia Elena y SAlinas Beristain, Laura (1997). Análisis comparativo de legislación nacional e internacional relativo a la mujer y a la niñez. Comisión Nacional de Derechos Humanos.

Quintana Osuna, Karla I. (2018). El caso de Mariana Lima Buendía: una radiografía sobre la violencia y discriminación contra la mujer. Cuestiones Constitucionales (38): pp. 143-168. https://doi.org/10.22201/ iij.24484881e.2018.38.11878

SEGATO, Rita Laura (2003). Las estructuras elementales de la violencia. Ensayos sobre género entre la antropología, el psicoanálisis y los derechos humanos. Universidad Nacional de Quilmes.

Suprema Corte de Justicia de la Nación (2013). Protocolo para Juzgar con Perspectiva de Género. Suprema Corte de Justicia de la Nación.

Secretaría de Seguridad Pública (2009). Protocolo para la atención de personas que han sufrido el delito de violación. Secretaría de Seguridad Pública.

YourcenAR, Marguerite (1985). Fuegos (7a. ed.). Ediciones Alfaguara, p. 26. 
Esta revista forma parte del acervo de la Biblioteca Jurídica Virtual del Instituto de Investigaciones Jurídicas de la UNAM
httos://biblio juridicas unam $\mathrm{mx} /$ biv DOI: http://dx.doi.org/10.22201/iij.24484873e.2021.160.15979

Universidad Nacional Autónoma de México, IIJ-BJV, 2021 